PROJECTS: THE CASE OF A NEW NUCLEAR REACTOR DEVELOPMENT

\title{
Authors' biographies
}

Stéphanie Tillement is Associate Professor in Sociology at IMT Atlantique (Social Sciences \& Management Department) and researcher at LEMNA. She coordinates the ANR project 'AGORAS', funded by "Investissement d'Avenir" and collaborates to the RESOH Chair. Her research focuses on organizational reliability and resilience, risk management in distributed work context, project-based organizing and innovation processes. She studies various sectors, notably railway and nuclear industries.

Frédéric Garcias is Assistant Professor in Strategy and Organization at Université de Lille (IAE Lille), and researcher at Lille Economie Management (LEM CNRS, UMR 9221). He collaborates to the AGORAS project (Action 3). His research focuses on learning and unlearning dynamics in large and complex projects and on the management of design capabilities.

Guy Minguet is Professor in Sociology at IMT Atlantique and researcher at CGS (Centre de Gestion Scientifique) of Mines Paris Tech. He collaborates to the AGORAS project (Action 3). His research interests are centered on design work and exploration processes

Florence Charue Duboc is Professor in Management of innovation at «Ecole Polytechnique » and research Director at CNRS (National Center For Scientific Research), I3-CRG (Centre de Recherche en Gestion). She collaborates to the AGORAS project (Action 3). Her researches concern the management of technical innovation, notably in multinational companies or involving inter-firms cooperation. She conducts researches with companies of various sectors (chemical, pharmaceutical, automobile industry, telecommunications) and mentors students in Master's degree and in doctorate on these themes. She published several articles and published three books. 


\title{
DISENTANGLING EXPLOITATION AND EXPLORATION IN HYBRID \\ PROJECTS: THE CASE OF A NEW NUCLEAR REACTOR DEVELOPMENT
}

\begin{abstract}
Using a qualitative research approach, this paper addresses a gap in the project management literature that is the coexistence of exploitation and exploration learning dynamics within a single large-scale and complex project. We investigate the case of the New Sodium Fast Reactor (NewSFR) project, a large-scale, complex and multi-actors project aiming at designing a new technology of nuclear reactor. Through a grounded, interpretive and multi-level methodological approach, we characterize NewSFR as a "hybrid project" that combines high exploration and exploitation goals. We investigate the 'hybridizing process' that takes into account long-term temporal dynamics and interactions between two levels of analysis: the knowledge areas within the project and the project itself. This enables to underline three major contributions. First, at a macrolevel, we highlight the ambiguity related to the difficulty for project members to agree on either exploratory or exploitative NewSFR status, which leads us to qualify it as a "hybrid project". We then investigate the case dynamically and at a micro-level, i.e. the level of knowledge areas within the project. We underline the temporal processes underlying the hybridization, and how it evolves in time through two data-based concepts: 'deliberate exploration' and 'emerging exploration'. We identify and categorize the main drivers of deliberate and emerging exploration throughout the project, and highlight how these drivers affect project management processes. We finally discuss the issue of managing such hybrid projects.
\end{abstract}


Keywords: project management, exploration/exploitation, hybridity, nuclear reactor, product development

\section{INTRODUCTION}

Adapting the modes of project management to the level of uncertainties or unknowns of a project is still a challenge for project-based organizations and an issue for scholars (Shenhar, 2001; Loch et al., 2006). In the current literature, this problem has mainly been addressed through the concepts of exploration and exploitation (March, 1991; Brady \& Davies, 2004). Yet, projects are labeled at a macro-level either as exploratory or exploitative (Lenfle, 2008), exploitative projects being defined as having "clearly defined goal within a specified period of time, and in conformity with certain budget and quality requirements" and exploration projects being those for which "neither the goals nor the means to attaining them are clearly defined from the outset" (Lenfle, 2016, p.47). The questions of how a project could be both exploratory and exploitative at the same time, and how such hybrid project should be appropriately managed (since the management processes of exploratory and exploitative activities are assumed to be radically different) is not clearly tackled in the literature. Existing studies on exploitation and exploration learning dynamics do not qualify precisely how and why these dynamics get entangled in projects and, more specifically, how this entanglement evolves along time and impacts projects' governance.

Using a qualitative research approach, our paper addresses a gap in the project management literature that is the coexistence of exploitation and exploration learning dynamics within a single large-scale and complex project (Davies \& Brady, 2016). We 
investigate the case of the New Sodium Fast Reactor $\left(\mathrm{NewSFR}{ }^{1}\right)$ project, which is a large-scale, complex and multi-actors project aiming at designing a new technology of nuclear reactor.

Through a grounded, interpretive (Gephart, 2004) and multi-levels methodological approach, we characterize NewSFR as a "hybrid project" (Chandrasekaran et al. 2015) that combines high exploration and exploitation goals. We analyze the 'hybridizing process' that takes into account long-term temporal dynamics and interactions between knowledge areas and the project. This enables to underline three major contributions. First, at a macro-level, we highlight the ambiguity related to the difficulty for project members to agree on either exploratory or exploitative NewSFR status, which lead us to qualify NewSFR as a "hybrid project". We then investigate the case dynamically and at a micro-level, i.e. the level of knowledge areas within the project. We underline the temporal processes underlying the hybridization, and how it evolves in time through two data-based concepts: 'deliberate exploration' and 'emerging exploration'. We identify and categorize the main drivers of deliberate and emerging exploration throughout the project, and highlight how these drivers affect project management processes. Finally, we discuss the theoretical and managerial implications of the hybridizing process in projectbased contexts, and present some limitations.

\section{THEORETICAL BACKGROUND}

\footnotetext{
${ }^{1}$ For confidentiality reasons, we use a pseudonym to designate the project, and later the organizations involved in project management and design.
} 


\section{Exploration / exploitation in projects: from global labeling to a fine-grained study of activities and knowledge domains within projects}

The concepts of exploration and exploitation have been introduced to differentiate two heterogeneous and conflicting forms of learning that coexist within organizations (Duncan, 1976; March, 1991). They are radically different in their characteristics and are competing for scarce resources. Gupta, Smith, and Shalley (2006) define these concepts as referring to "orthogonal" types of learning processes and activities. The use of these concepts has spread in many fields of the management literature, without really removing the ambiguities contained in March's theorization, which has paved the way to multiple interpretations and appropriations by researchers (Garcias, Dalmasso, and Sardas, 2015). In this paper, following Greve (2007), we refer to "exploration in product innovation" and define the notion of "organizational exploration" as the "search for new knowledge, use of unfamiliar technologies, and creation of products with unknown demand" (p.1). In a previous article, Greve (2003) described the R\&D innovation process through a case study (shipbuilding) drawing on the seminal distinction between "problemistic search" and "slack search" (Cyert and March (1963: 127). The first concept defines a plausible dynamic by which organizations learn from reflexivity on performance. The second one refers to an institutionalized dynamic based on added resources for an assumed exploratory orientation. Greve's model suggests that in both cases (problemistic search and slack search) the existence of a problem (i.e. performance below aspiration level) is the engine that drives innovation dynamicity.

A company that explores is often presented as one that distances itself from the knowledge sets that it applies to its usual processes, breaking with its usual knowledge. Li, Vanhaverbeke, and Schoenmakers (2008) introduce the notion of "search distance" to 
reframe the opposition between exploration and exploitation, after conducting an extensive literature review on how exploration and exploitation are conceptualized. Building on the assumption that the key question is always "whether the new knowledge is familiar or unfamiliar, compared to a firm's existing knowledge base” (p.108), they define explorative activities as dealing with "distant knowledge". But they also elaborate this notion of "distance", claiming that it could refer to three fundamentally different types of distance: knowledge may be "distant" from the existing knowledge-base of an organization in terms of cognition, space and time. Cognitive distance is a "matter of substantial content of knowledge". Spatial distance "refers to the knowledge search crossing physical space". And finally, temporal distance "examines the role of time and the tension between exploitation and exploration" (p.116).

In the field of project management, the differentiation between exploration and exploitation processes has been mainly used at the project level. Two lines of work emphasize how the distinction between exploration and exploitation operates within the field of project management. The first one is focused on temporal sequencing between different types of learning within a given project. The second one has more recently claimed for a clear distinction between radically different types of projects.

A first group of research work considers that projects are less and less exploratory over time. This is often the underlying assumption of work on stage-gate project management processes (Cooper, 1983), which shows that projects are funnel-shaped, with a highly exploratory "fuzzy-front end" gradually being replaced by an exploitation orientation (Reid \& De Brentani, 2004). In the same vein, Midler, studying the course of a project, has shown how the latitude of action is progressively reduced as the amount of accumulated knowledge increases (Lundin \& Midler, 1998; Midler, 1995). This research 
emphasizes the relatively linear nature of projects, and the irreversibility of the process that leads from exploration to exploitation. This literature is mainly situated in the wake of research on the improvement of a "standard" model of projects, resulting largely from observation of the practices of the automotive industry, where the "heawyweight project management" (Clark \& Fujimoto, 1991) has long been a dominant model for development projects.

In a second group of research work more recently developed, the opposition between exploration and exploitation has served as a basis for the development of a "contingent" approach to project management, which has become more and more important in recent decades (Howell, Windahl, \& Seidel, 2010; Shenhar, 2001, Lenfle, 2008). For the proponents of this approach, not all projects can be managed in the same way, because of fundamental differences in the level of uncertainty or unknownness which characterizes the projects. This stream of research has criticized an overly prescriptive approach to project management based on a "one best way", and showed that conventional rationalist methods are not relevant for managing projects that are essentially "exploratory" (Lenfle, 2008, 2016; Sethi \& Iqbel, 2008). As a result, the project management literature is increasingly split into two separate streams, one devoted to the study of exploration projects and the other dedicated to the study of classical development projects to integrate and exploit already developed knowledge. However, it should be noted that, based on this legitimate concern for a "fit" between management modes and the nature of knowledge leveraging, the literature has gradually come to use the concepts of exploration and exploitation for qualifying projects as a whole, which can actually overlook the plurality of types of learning processes and activities intertwined in each project. 
Thus, sofar the project management literature tacitly conveys the idea of a uniformity of learning processes within projects or within a phase of a given project. As a result, studies that deal with the coexistence of exploration and exploitation within projects are situated at the level of project portfolios, seeking the right balance between exploratory projects and exploitative projects (Andriopoulos \& Lewis, 2008). This research on portfolio techniques complements classic results in the field of $R \& D$ management related to project portfolio management capabilities (Clark \& Wheelwright, 1992). But it also assumes a uniformity of learning processes within projects, and adopts a point of view outside the internal dynamics of the project, which is the portfolio manager's perspective. Consequently, little work in the field of project management has considered the possible hybridization of exploration and exploitation within a given project (Chandrasekaran, Linderman, \& Schroeder, 2015; Eriksson, 2013).

A few steps in this direction have however been made very recently in the field of management of so-called "complex projects" (Davies \& Brady, 2016). As these authors state, "large and complex projects have to perform regular, repetitive and predictable project routines when conditions are stable and predictable, whilst at the same time promoting innovation to deal with unexpected, rapidly changing and novel situations. Complex projects are really a 'conglomerate' of unique tasks and new procedures applied for the first time and highly standardized and repetitive tasks that have been exploited on previous projects" (p.10). But the way project managers concretely deal with this agglomeration of routine and innovative tasks in complex projects remains largely unexplored until now: "Prior research largely focuses on how firms develop dynamic capabilities to manage a portfolio of embedded projects. With a few recent exceptions, research rarely studies how dynamic or project capabilities are deployed to manage large- 
scale, complex and uncertain projects, such as weapons systems, oil and gas platforms, rail transportation links, nuclear power plants, energy networks and airports” (ibid.).

The entanglement between exploration and exploitation learning processes within a project has not been studied per se though its existence in complex projects has been outlined. We intend to address this gap with our research.

In these research works, each exploration process refers to a delineated knowledge domain, we thus qualify this perspective as micro-level compared to the macro-level of the project which combines several knowledge areas. Thus in order to better understand how the exploration and exploitation learning processes entangle within a project we propose to develop our analysis both at the macro level of the project and a micro level. As the literature claims for a contingent approach to project management depending on whether the project is exploratory or exploitative, how do the actors determine whether the project belong to one of these categories? Does this categorization cover the whole project or some activities within the project? Do the various actors involved agree on the categorization? Is it possible to determine this at the beginning of the project or is it to evolve along the project course? If exploration and exploitation learning processes coexist within a project, how is it managed?

\section{RESEARCH METHODS}

The study presented here is part of a broad, ongoing research program that started in 2014 for a six-year period. It gathers academic and industrial partners, including the industrial leader in charge of designing the nuclear island (later referred to as AtomCO) and the Safety Technical Support Organization (later referred to as TSO), both involved at different levels in NewSFR project. 
In order to tackle the research questions outlined above, we undertook a longitudinal analysis of a single case. To reveal the complex processes at the basis of the phenomenon under study, i.e. the coexistence between exploration and exploitation dynamics within a project, we chose to adopt a qualitative approach based on a single case study. A qualitative study is particularly well suited to answer how and why questions (Rowley, 2002) and to explore "a contemporary phenomenon within its real life context" (Yin, 1993, p. 13). Using a variety of evidence from different sources (i.e. documents, interviews, non participative observation) supports deep and detailed investigations of exploration and exploitation processes and of how this coexistence evolves, clarifies or becomes more complex over time. Our research design aims at reconciling macro and micro units of analysis, i.e. the project and "knowledge areas" within the project.

The case we had the opportunity to study is a large-scale, complex project in which several uncertainties remained at its launch. NewSFR consists in the design of a new generation of nuclear reactor, based on the sodium technology. This mega-project aimed at designing a large industrial infrastructure in the nuclear sector, which closely combines innovative activities and replication of existing and regular solutions. This project is thus particularly relevant for our research question as it requires simultaneously exploration, i.e. the search for new and distant knowledge, and exploitation, i.e. the reuse and refinement of local and existing knowledge. In this respect, it constitutes a very fertile case. In addition, NewSFR, as a project "in the making" offers the opportunity to have access to 'real-time' data regarding project members' interpretations, engagements and relationships as the project progresses. This enables to follow how the processes unfold when new areas of exploration emerge during the project, and the associated specific circumstances. 
The research employs an interpretive design (Gephart, 2004) to extend existing literature on exploitation and exploration dynamics in a project-based context by developing new theoretical propositions and not to test hypothesis in a deductive logic. Our research design can be described as theory building from a case study (Eisenhardt \& Graebner, 2007), in that we elaborate concepts from our data analysis to describe social ongoing processes not well described yet in literature.

\section{Research site}

The case investigated in this research is a mega-project named NewSFR. NewSFR is designed to be one of the first "Generation IV" (Gen IV) nuclear reactors worldwide. As such, NewSFR must demonstrate its ability to reach the main goals assigned by the Gen IV International Forum (GIF) ${ }^{2}$ : safety, operability, ultimate nuclear wastes transmutation and a mastered investment cost. In the case studied, the choice was made to dedicate efforts to the Sodium Fast Reactor (SFR) technology, one of the six retained by the $\mathrm{GIF}^{3}$. Although supposed to be a breakthrough, SFR technology is not really new: it has already been built and operated by the actors who are now engaged in the NewSFR adventure through three nuclear reactors, ranging from the experimental reactor to the industrial demonstrator, which will later be named ExpSFR, SFR $\alpha$ and SFR $\beta$. The last Sodium reactor was stopped in 2010 because it reached the end of its operating life.

Mainly publicly funded in the amount of 650 million euros to cover (only) the design phase, this project has begun in 2010 and is expected to continue until 2019, if not more,

\footnotetext{
2 The Generation IV was launched in 2000 by the Department of Energy (USA) in order to renew and stimulate researches on future nuclear technologies worldwide.

${ }^{3}$ With the main goals of Gen IV reactors in mind, more than 100 experts from 12 countries selected 6 concepts (among about 130 evaluated) as the most promising for Research and Development: Gas-cooled Fast Reactor (GFR), Lead-cooled Fast Reactor (LFR), Molten Salt Reactor (MSR), Supercritical Watercooled Reactor (SCWR), Very High Temperature Reactor (VHTR) and Sodium-cooled Fast Reactor (SFR).
} 
depending upon the political decision to implement detailed design. The construction of the demonstrator was initially planned around 2025 (Figure 1) and the industrialization around 2050, should it happens.

Figure 1: NewSFR schedule (source: Boullis, 2015)

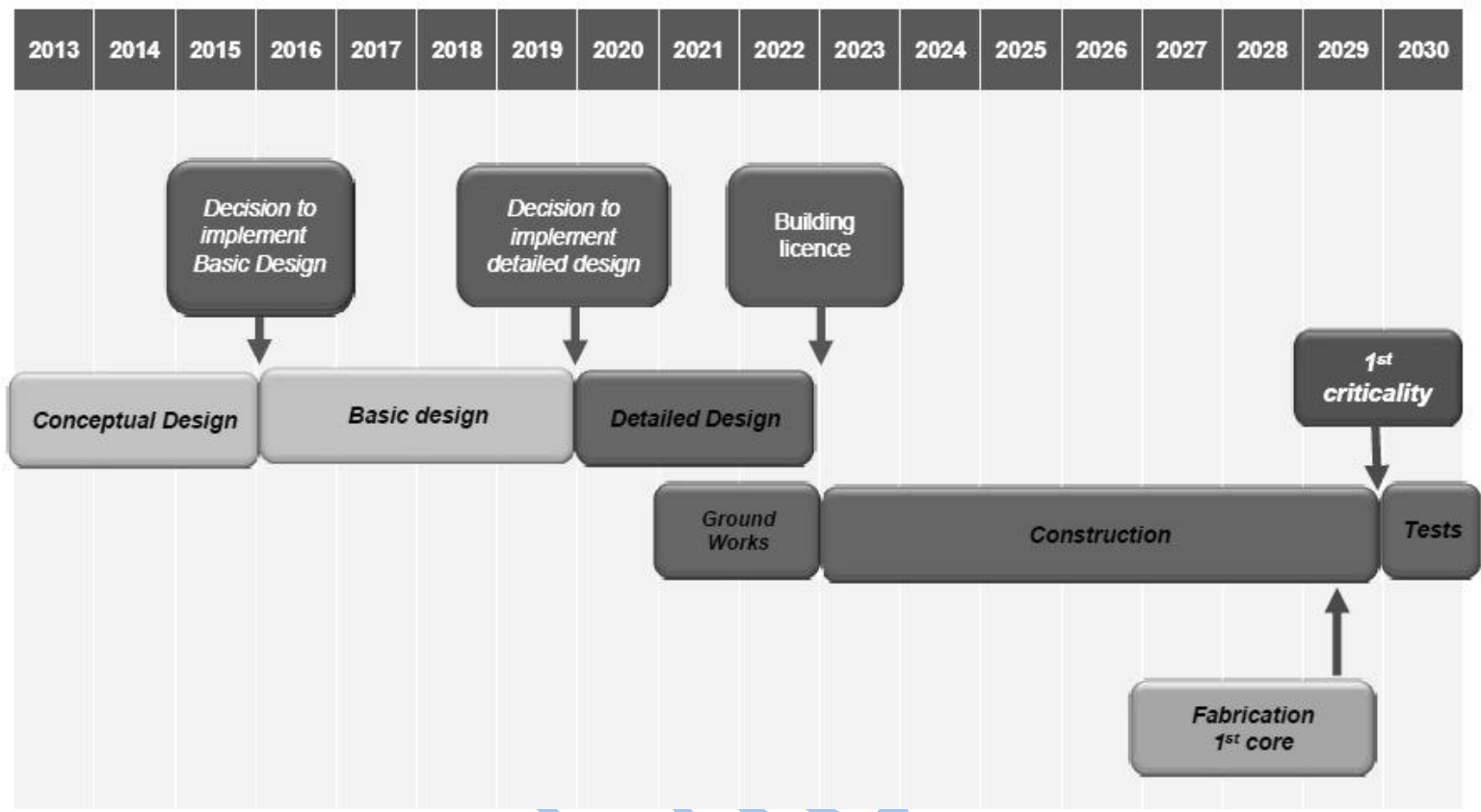

More than 600 people are currently working on the design of NewSFR, half of them at $\mathrm{BSC}^{4}$. The core of the project is entrusted to the historical key nuclear actors: BSC, EnergyCo $^{5}$ and AtomCo ${ }^{6}$. The project is officially managed by the BSC reactor engineering department, through the NewSFR project unit. This unit is connected with the BSC reactors' study department and is constituted by a project manager, an industrial architect who assures the function of lead contractor, a project manager (in charge of the organization, risks control, costs and delays monitoring) and engineers in charge of managing engineering design areas. EnergyCo is the assistant to the contracting authority. AtomCo ensures the design of the nuclear steam, the nuclear auxiliaries and control-

\footnotetext{
${ }^{4}$ BSC, for Big Science Center, designates a public organization in charge of fundamental and industrial research in energy, and notably on nuclear energy.

${ }^{56}$ Pseudonyms.
} 
command, as well as the general installation. Together with this main core, 11 industrial partners are engaged in the project (Alstom, Bouygues, Rolls Royce...). The project also gives rise to international collaborations including Russian and Japanese. Cooperation modalities between these diverse actors stay vague, despite some partnership conventions or project reviews and coordination meetings.

Besides actors directly involved in the design of NewSFR, the Nuclear Safety Authority (NSA) and its Technical Support Organization (TSO) are in charge of evaluating the safety of technical options taken in the design of the reactor. They have also participated to the GIF, mostly regarding the safety requirements of Gen IV concepts.

Using a single case study, our primary unit of analysis is the project itself, which involves multiple organizations. The embedded units of analysis are several "knowledge areas" within the project (e.g. civil engineering, functional architect, nuclear core, safety). The choice of these knowledge areas was mainly guided by field access constraints, and notably the fact that their corresponding managers belonged to AtomCo.

\section{Data collection}

Data collection started in April 2015 and is to continue until 2019. Two main types of data were collected: semi-structured interviews and documents. Having AtomCo and TSO as partners of the research program gives us privileged access to people of these two organizations who are involved in the project and almost all the interviews were conducted with them ${ }^{7}$. This ensures an iterative process of field data collection and analysis (Gephart, 2004). It guarantees the possibility to collect data over a significant

\footnotetext{
${ }^{7}$ We also organized collective interviews with people from the academic and political sectors, but as we did not use these data in this paper, they are not presented.
} 
period of time and to return regularly to the field to collect new data on a specific emerging question or to refine research hypothesis or findings.

Interviews. Up to now, we have conducted 23 interviews (table 2), mainly with AtomCo engineers and managers. In order to limit bias, we chose highly knowledgeable informants, who had diverse perspectives on the NewSFR project. Our data set includes organizational actors from different hierarchical levels (e.g. project manager, technical managers or engineers), technical or functional areas (e.g. civil engineering, mechanical engineering, safety) and with differing seniority. We have also interviewed actors from external relevant organizations, mainly experts from TSO. Many of the engineers or experts that we have met had participated to the operation of SFR $\alpha$ or SFR $\beta$. Their longterm experience where very valuable to investigate temporal exploitation and exploration.

Table 1: Data collection

\begin{tabular}{llcc}
\hline AtomCo & Project manager (PM) & 4 & $2015,2016,2017$ \\
& $\begin{array}{l}\text { Functional architect (FA) } \\
\text { "Civil Engineering" technical }\end{array}$ & 3 & $2015,2016,2017$ \\
manager (CEM) & 3 & $2015,2016,2017$ \\
"Nuclear core" technical manager & 2 & 2016,2017 \\
& $\begin{array}{l}\text { (NCM) } \\
\text { "Mechanical" technical manager }\end{array}$ & 1 & 2017 \\
& (MTM) & & \\
& Technical engineer (SCE) & 2 & 2017 \\
& Project safety engineer (PSE) & 2 & 2015,2017 \\
& Safety expert 1 (SE1) & 2 & 2015,2017 \\
& Safety engineer (SE2) & 1 & 2017 \\
& & Total: 20 & 2015,2017 \\
\hline TSO & Safety Engineer 1 (SE1) & 2 & 2017 \\
\hline TOTAL & Safety Engineer 2 (SE2) & 1 & \\
\hline
\end{tabular}

Formal interviews lasted from 90 to 180 minutes in length. They were conducted individually in private offices and meeting rooms, taped and recorded (unless otherwise 
agreed). During these interviews, participants were asked to describe their professional background and how they got involved in the design of NewSFR (or in evaluation of Gen IV concepts in the case of TSO experts), their role in the project and their relationships with other participants of the project (within the same organization or another). We also ask about their perception of NewSFR past and future trajectory, its link with other reactors (e.g. SFR $\beta$ or $\mathrm{EPR}^{8}$ ), and the complexity and uncertainties inherent in this project. We pay special attention to the way they were talking about knowledge transfer or creation, and about tensions between exploration and exploitation within the project regarding specific "knowledge areas" (e.g. decision of launching R\&D on a new technical solution that has not been evoked before).

Documents. We collected different documents referring to NewSFR project, from different sources: BSC annual public reports, power point presentations and publications from members of NewSFR project, safety analyses. These documents (around 600 pages) brought a technical basis to understand the project and gave us access to the official or institutional vision or "ways of describing" NewSFR, its goals, schedule, and how official descriptions have evolved in time. Collecting these documents were also helpful to crosscheck the interviews and limit bias.

\section{Data analysis}

All the interviews were transcribed and then coded. To analyze our data and build theory, we adopt an iterative and mostly inductive approach (Miles et al., 2014).

From the beginning of our study, we had identified the area of research that we wanted to contribute to, i.e. knowledge management and learning dynamics in mega-projects. The main categories have emerged from an iterative process of data collection and emergent

\footnotetext{
${ }^{8}$ European Pressurized Reactor
} 
interpretation (Gephart, 2004). Given the extreme characteristics of NewSFR (revolutionary and evolutionary, embedded in past histories and pulled by innovation, the importance of long-term dynamics), we chose to analyze our data through the lens of the literature on exploration and exploitation. The core categories are data-grounded but they have emerged from a first round of coding during which empirical material was analyzed with the 'exploration/exploitation' theoretical framework in mind. This enabled us to define four core categories that are in direct link with this literature: temporal exploration, cognitive exploration, exploitation logic, juxtaposition of exploitation and exploration. Once these core categories were chosen, we returned to our data set (around 550 pages) for a second round of coding. We read transcribed interviews in detail and coded them using NVivo software to elaborate more precise categories that were related to our specific case and research question. Through this work, refined sub-categories have emerged (Figure 2). For example, data analysis enabled us to split the core category "cognitive exploration" into several sub-categories, mainly "deliberate exploration", "emerging exploration", "exploration drivers", "cognitive distance" and "arguments against exploration".

We first identified the sub-categories by coding three interviews. We then applied these categories on all our data set.

The identified categories are the foundations of our theory building. They enabled us to label data grounded concepts that support our theoretical propositions. The findings presented in next section directly arise from these concepts. Since this study is part of a long-term research program, we will be able to refine emerging concepts by returning to the field and collecting more data. 


\section{RESULTS}

In this section we present the three main findings that arise from the analysis work. First, at a macro-level, we qualify the status of NewSFR project as ambiguous and not clearly labeled either as mainly exploitative or exploratory. We then investigate the case at a micro-level, i.e. the level of knowledge areas within the project. We underline the temporal social processes underlying exploration activities within the project. We propose two data-based concepts: 'deliberate exploration' and 'emerging exploration'. Finally, we identify and categorize the main drivers of exploration throughout the project, and highlight how these drivers affect innovation and project management processes.

\section{The ambiguous status of NEWSFR as regards to exploration and exploitation at the} project level

From the beginning the objectives assigned to the NewSFR project included elements referring to a dimension of technological breakthrough as well as an ambition of realism and industrial feasibility and capitalization on the previous achievements of the sodium sector. As shown in NewSFR documentation (see table 2), the project is qualified both as revolutionary (as a Generation IV innovative concept) and evolutionary (as relying on the experience of previous SFR operated in the past). The goal of the project itself is torn between exploration and exploitation learning dynamics.

Table 2: Tensions between exploration and exploitation dynamics related to NewSFR project (identified from public documents)

\begin{tabular}{|c|c|c|c|}
\hline $\begin{array}{l}\text { Data } \\
\text { source }\end{array}$ & $\begin{array}{c}\text { Official description of NEWSFR } \\
\text { missions }\end{array}$ & $\begin{array}{l}\text { Learning } \\
\text { dynamics }\end{array}$ & $\begin{array}{l}\text { Type of } \\
\text { projet }\end{array}$ \\
\hline Public & "NewSFR's primary objective is to & Exploration & Revolutionary \\
\hline BSC & demonstrate its ability to re-cycle & & \\
\hline report, & recoverable materials. The interest of such & & \\
\hline 2012, Vol. & systems is widely shared at the & & \\
\hline
\end{tabular}




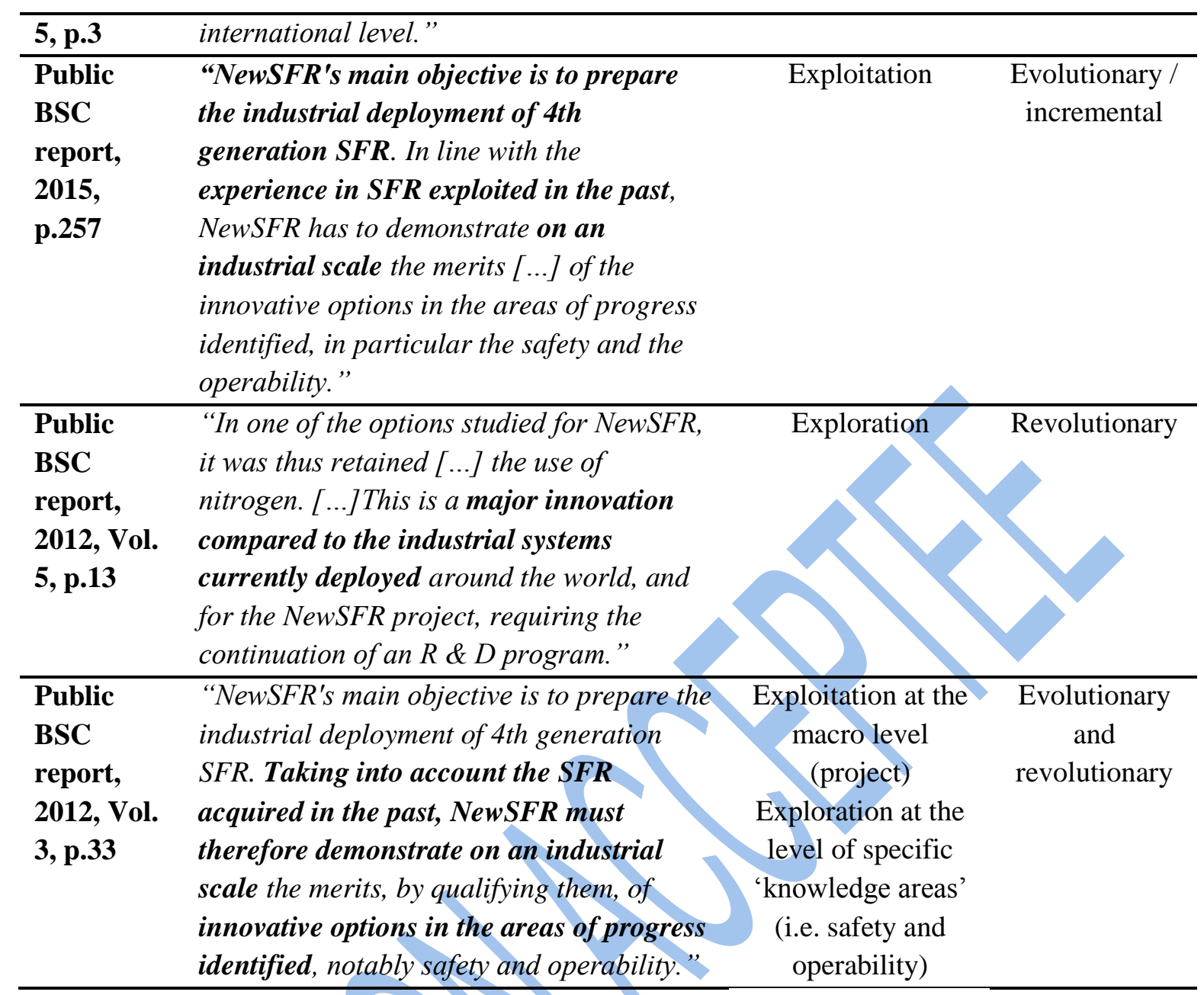

These dual goals were reflected in the overall characterization of the project by the actors.

For this TSO specialist in sodium reactors, the duality of NewSFR objectives is here clearly formulated, linked to different visions carried by the members of the consortium:

"It seems to me that AtomCo has capitalized a lot on the EFR [European Fast Reactor] project. I think that from the point of view of the BSC, the idea was more to make a "Generation 4", that is to say a technological breakthrough and the opportunity to innovate on the major equipments of the reactor including the core." (TSO, $\left.\mathrm{SE}_{1}\right)$

While it is to be expected that, at the beginning of a project, the actors clearly perceive whether it is an exploitation project in continuity with previous achievements, or an 
exploratory project that aims at generating technological breakthroughs, the comments of some actors show that this question does not have a clear and shared answer.

"NewSFR is either a prototype or a power plant at the industrial size. But now I do not always know where it is." (At, $\left.\mathrm{SE}_{2}\right)$

Several actors thus express a difficulty in exactly identifying the status of NewSFR, in an industry accustomed to classifying projects between those with 'research' objectives and those aiming to operate on an 'industrial' scale, with specific performance objectives.

"There is a question of substance, which is occasionally asked by people but remains unclear: what exactly is NewSFR for? Between the experimental vision that some people of BSC clearly have (for them it would be a magnificent toy, it would be beautiful!) and the industrial demonstrator vision, the path is narrow." (At, CEM)

Others express more directly the idea that NewSFR is in fact a contradictory, even chimerical project aimed at reconciling opposite objectives of economic realism and radical innovation:

"Q: Currently NewSFR is designed as an industrial prototype reactor with an experimental dimension or..

A: That's right, it is trying to please daddy, mommy, grandpa, granny... !" (At, CEM)

This ambiguity can first be interpreted as reflecting the ambivalent status of the sodium reactors' technology. This technology is characterized by the fact that it is quite old (first reactors dating from the 1960s), with a number of significant experiments in the world, but also that it never went to a real industrial stage, to the contrary of the PWR (Pressurized Water Reactor) technology for example. The sodium reactors' technology appears to be stuck in an in-between state: it is not really at the "artisanal" stage of reactors devoted only to research, but we cannot speak either of an industrial heritage about it. In fact, the characterization of the sodium technology as "industrial" or not 
depends on the criterion chosen: if we compare it with the PWR technology, we cannot legitimately speak of "industry". But if we consider all past achievements, we cannot say, far from it, that this sector is at the stage of the "blank sheet":

"PWR technology now is pretty established while the SFR are less, much less ... [...] There are few commercial SFR and they are all different... it is quite varied so we cannot say that there is really a "sector" that emerges... There have been adaptations (rather "wooden legs'), changes, but there are still about twenty reactors that are quite close to each other, the United States must have reactors a little of the same style... when about twenty reactors have been built, it is not an artisanal object anymore." (TSO, $\left.\mathrm{SE}_{1}\right)$

These ambiguous statements confirm that NewSFR is in the wake of a technological legacy of uncertain status, with a significant series of achievements but without any industrial standardization that could allow NewSFR to simply and easily follow an exploitative logic. Moreover, the way in which NewSFR assimilates or not the technological heritage of the sodium sector is far from obvious for many actors.

"It is true that we have all the "background" of the past but we still try to detach as much as possible, to have a new mindset." (TSO, $\left.\mathrm{SE}_{2}\right)$

However, this seems to be counterbalanced by the fact that the sodium reactors themselves, and in particular NewSFR, share many common points with the PWR reactors. This can go so far as to call into question the idea that SFR reactors constitute a truly different pathway to PWR reactors, with significant impacts for the design and construction of NewSFR.

"Overall, there is a capitalization of skills, because it is nuclear, so there is still a significant 'common ground'. There is a common basis and at the same time specificities. [...] Sodium reactors have their specificities. It remains that they still have a big common core with PWR regarding safety analyzes." (At, $\left.\mathrm{SE}_{2}\right)$ 
Thus designing NewSFR, when one has general skills in the field of nuclear reactors of any type whatsoever, does not imply to 'reinvent the wheel' permanently:

"Here we have a good return of experience: we have vapor exchangers that look like those that have been used on SFR reactors in the past but especially it also strangely resembles the steam generator used in the current fleet of PWR reactors. The strongest feedback is due to the PWR fleet, we still have a similarity from an architecture point of view, operation, manufacturing, and control, all which is standard!" (At, MTM)

It can thus be seen that, depending on the components or characteristics in question, NewSFR is at different levels in continuity, both with respect to the previous SFR type reactors, but also with respect to the PWR reactors. The question of continuity with a technological heritage and previous achievements, on which is partly based the characterization of a project as exploratory or exploitative, is therefore complex in a way that prohibits a simplifying approach to the project as a whole.

In addition, there is a key feature of technological experimentation processes in the nuclear field, which is the size of the objects to be designed and built. Indeed, on such large and complex objects, it is impossible (because it would be too expensive) to multiply the prototypes before reaching an object ready for industrial use:

"In order to test the machine it must be almost full size but it is expensive so... it is clear that we will not do as in the car industry where they can do fifteen or twenty prototype cars that they will crash ... So we will make loops, iterate, we will do things to the maximum... the seed is still something quite experimental..." (TSO, $\left.\mathrm{SE}_{1}\right)$

This constraint linked to the scale of products leads to the relatively early design and construction of hybrid objects, in the sense that they have not yet quite an industrial maturity, but must already enable to experiment an operating at an industrial scale. 
Put together, these elements, summarized in Figure 3, blur the possibility of perceiving the NewSFR project as either uniformly exploratory or exploitative, and contribute to make it an indeterminate project, hybridizing the characteristics of one and the other of the "ideal types" of projects. We thus propose to qualify it as a hybrid project.

Figure 2: NEWSFR as a hybrid project

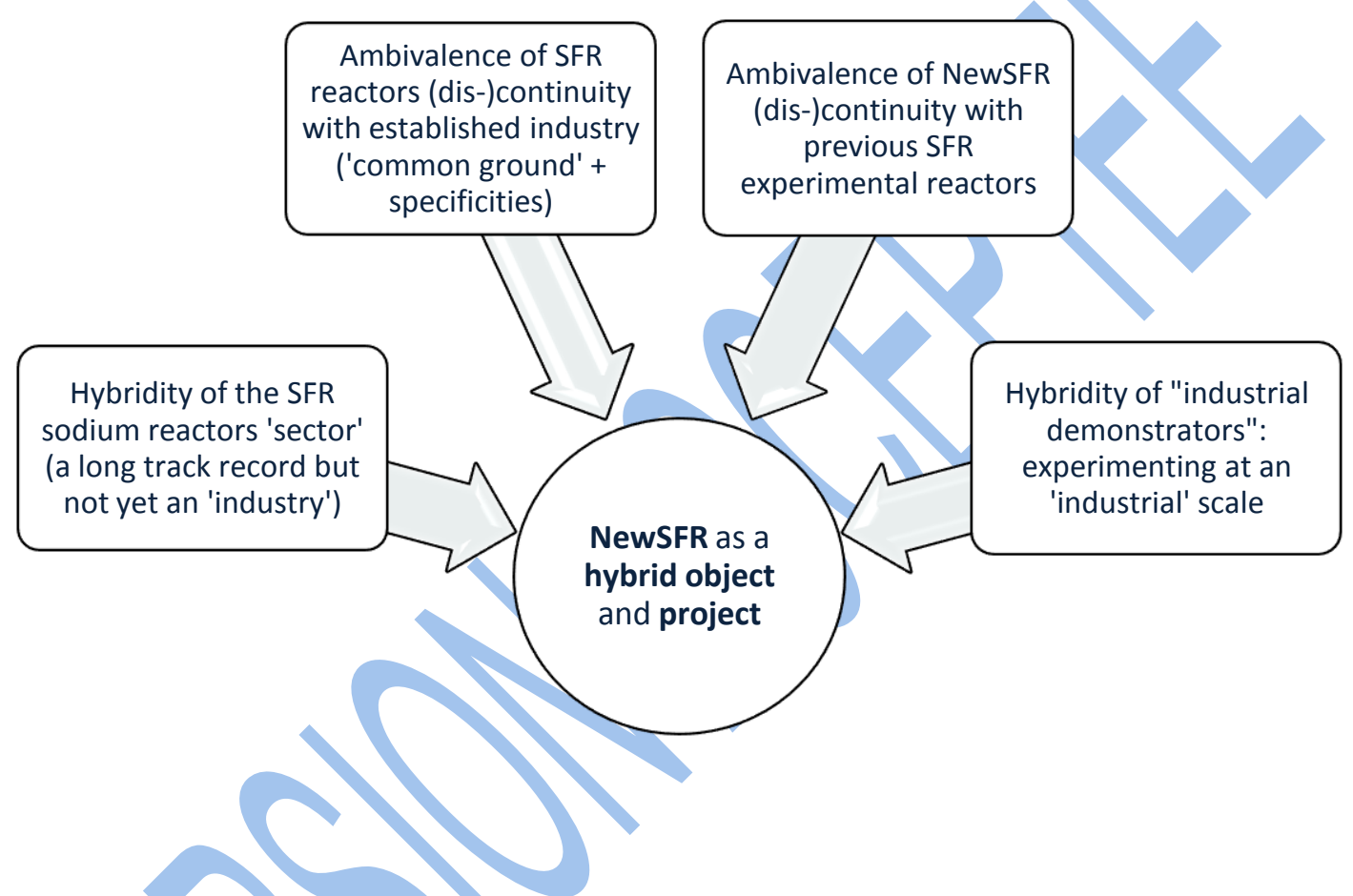

This hybrid dimension, which refers to a clear hybridization between exploration and exploitation at a macro-level, i.e. the level of the project, thus opens up an area of uncertainty about what the project actually is, which leaves the main institutional actors (i.e: BSC and AtomCo) free to try to impose their own vision of what the project should be and how it should be ruled. The progress of the project thus appears as the field of a 'clash' between rival visions, BSC willing to take advantage of the project to push experiments on the sodium sector, AtomCo willing to achieve a feasible economic realization for the creation of a real 'industry' of sodium reactors. This clash of visions is clearly expressed by the AtomCo project manager: 
"We tried to set boundaries, to say we do not reopen everything about everything .... We have a small problem that is that BSC is less framed than we are." (At, PM)

This contrasts with the way the project was conceived and presented when it was launched, and the reasons why sodium was chosen as a technological solution. Indeed, opting for sodium was a question of retaining the solution that made it possible to reach the horizon of an industrialization of technology as quickly as possible, while achieving the objectives of GIF:

"There were two options, and it is linked to the GIF: either we do something in the short term, or we do it in the long term. In choosing 2020 as a goal, it was necessary to rely on something existing." (At, $\left.\mathrm{SE}_{2}\right)$

"Relying on something existing" concretely would have led to the massive reuse and exploitation of the past achievements of the sodium industry, these past achievements being like a "treasure":

The "treasure", as they say, is all the investments that have been made for generations on this sector. It is true that we must wonder if we go into a dead end, and then we should not have any scruples. But if we wanted to meet the objectives announced there were not many other choices for us [than sodium]! (At, $\left.\mathrm{SE}_{2}\right)$

At the project level, this hybrid status is associated to ambiguity: ambiguity about the areas in which exploration is legitimate, ambiguity about the extent to which exploration is present in the project, ambiguity between actors on these questions. In order to better characterize the balance between exploration and exploitation processes, how it evolved over time and the issues risen in the project management, we developed our analysis at a micro-level, i.e. the level of sub-projects or knowledge areas. This is the purpose of the next section. 


\section{Deliberate and emerging exploration: understanding macro-level entanglement through the prism of knowledge areas}

Adopting a micro level perspective, i.e. the level of sub-projects or knowledge areas, we propose two concepts based on our data analysis, which differentiate two types of exploration processes that coexist within the project: 'deliberate exploration' and 'emerging exploration'.

From the beginning of the project, "deliberate exploration" is present on specific knowledge areas, mainly the one associated to the reactor core. This concept refers to knowledge creation on specific knowledge areas that has been agreed from the beginning of the project by all the contributors. Because of this deliberate exploration, actors tend to present NewSFR as an innovative concept and to explore technical solutions that clearly differentiate NewSFR from previous SFR.

"Basically, BSC's rhetoric is very simple: why do we develop NewSFR? We do because there are three new facts that are worth reopening the case. We have a new reactor core (it has not been completely proven but it's globally true). There is a technological breakthrough in terms of core operation between NewSFR and SFRß. This is fundamental! We even give hope that maybe we won't have any serious accidents. We are not sure, but there is a clear gap on core design and operation, especially in accidental operation. [...] So BSC says: "I am designing a new core!" so all we knew before, you throw it away, the concept is based on other considerations. Secondly, inspection was a weak point of previous SFR because sodium is not clear. We have made significant progress on this issue by developing new reflectrometry equipment. [...] Really substantial progress because AtomCo achieved a world first." (At, PM)

Yet, apart from deliberate exploration, agreed on from the beginning of the project, innovative technological choices are progressively taken and the project goals become 
increasingly oriented towards exploration, through "emerging exploration", at the expense of exploitation goals, and thus reducing the potential for a rapid industrialization. We define "emerging exploration" as the preference given to novel technological solution that was not envisioned at the beginning of the project and for which exploration learning in a specific knowledge area is required. The "energy conversion system" (ECS), which is an important subsystem, is a perfect example of "emerging exploration". Historically all reactors have operated with a water-steam conversion system, and the first choice was to use the same system in the design of NewSFR in order to exploit previous knowledge. But BSC has been working for years on systems based on the principles of the "Brayton cycle", of the sodium-gas type, while it has never been implemented. Progressively, BSC has pushed this technical solution, which has led to a reinforcement of exploration processes in the project. The first and classical system is not totally abandoned, but both systems, the routine and the innovative ones, are developed and designed in parallel.

"BSC has changed recently gear. He asked us to work on a preliminary design on the gas conversion system scheduled for the end of 2017. We already have a NewSFR preliminary design on the water system, this is the technical dossier that we have provided in 2015 and we have to do a new dossier coupling NewSFR with Brayton cycle with the same level of maturity than the 2015 dossier. The aim is to have all the necessary elements on the table in order to be able to compare both systems." (At, PM)

Project teams are thus studying both systems in parallel, which requires simultaneously exploitation and exploration learning. The choice of a sodium-gas solution has farreaching consequences for the rest of the project, in that it orientates the project in a much more experimental way than initially envisaged, in particular by EnergyCo and AtomCo. This has also important consequences in terms of project management, i.e. in terms of cost and delays. 
"Yesterday, during a project review, we said that we had two schedules. In fact, it's not two; it's three, four, five! I don't even know. [...] According to the technical options, the sequencing is different. Don't anticipate that each one of these systems, water-conversion system versus gas-conversion system, can be implemented at the same time! [Laughs] These technical options are totally different and the level of maturity of the gas-system is very low. If it's an experimental reactor, well... we may have been a bit excited. But if it is an industrial prototype, or even a technological demonstrator, in this case it would be necessary to cut the experimental options." (At, CEM)

The entanglement between exploration and exploitation, even within specific knowledge areas, destabilize the project as a whole as well as people working for the project. Engaging in emerging exploration has caused the number of technological locks to rocket.

"As engineering departments, we have a dirty hands approach that leads to discover many technological locks. We discover locks every day! For example, we wonder: "ok, but now how do we start the power plant, how do we stop it? And then, what happens? Etc." And we don't have any answers because all this has not been a direct area of focus". (At, PM)

Surprisingly, instead of being reduced as the project progresses, as underlined in stagegate project management literature, the emerging exploration dynamic leads to increase the confusion and the ambiguity that we have highlighted at the beginning of the project. Emerging exploration also tends to blur temporal markers and the positioning of the different project stakeholders. Far from being linear or sequential, the design process rather appears turbulent.

"In fact, we are told to go back to basic design within two years from now, but in practice we are still in a conceptual design for a certain number of topics." (At, FA) 
Labeling precisely the types of design activities that managers and engineers carry out is difficult. This affects the way the project is or can be managed, so that some question the existence of any project steering:

"We should know the objective of the current industrial set-up. Is it really intended to make a detailed preliminary program as we are supposed to do until 2019? A detailed design means that we're going to build it! Or that you think you're going to build it! But today, nobody honestly thinks that we're going to build it: there is no operator, and no one is really willing to fund it. Now, we are in a "basic design" without a name, or it does have a name: it's said now! [...] So we remain on stand-by and we can still manage uncertainties. We need a robust industrial set-up for the implementation, and we don't have it now. [...] they could try to organize for an appropriate project steering, either based on the costs or on safety, but today there is no project steering. Safety must be ++ , costs should be - - and in the midst of all this, we, as lead contractor, are stuck because the structure is too big, or too small, or too costly, or too whatever!... it's delicate, it's delicate! And actually, there is no guideline! We're trying to set our guideline, but when we do, they disagree... and yet, they're not able to set another one." (At, FA)

"I think that the situation today is yery ambiguous because no real choice has been made at the end of the year. [...] By the end of 2017, we'll have studied the gas conversion system whose configuration will be in significant gap with the water system at the end of preliminary design. So if nothing is done, we will compare apples and oranges!" (At, CEM) Emerging exploration at a micro level calls into question the goals and the viability of the project at a macro level. Engineers and managers who are involved in the project doubt that the project will reach industrialization one day.

"I wouldn't say that we are never going to build it. I would rather say that we cannot do it as it stands at the moment precisely because it is not well defined, it remains multifaceted and it remains very costly since it's supposed to meet all requirements. So, for sure, it 
cannot be built in its current state. At least to me! So the 4-years linear path that has been set is likely to be disrupted at the beginning of 2018. Maybe at this point, we'll have an idea of what might happen within next two years, and yet, there will inevitably be a break, a technical break and most probably an organizational break." (At, FA)

A micro-level analysis has revealed the underlying processes leading to more and more exploration processes within the project. These processes of deliberate or emerging exploration lie at the level of knowledge areas within the project. Yet, by inducing more and more uncertainties of different types (schedules, design work, project organization...), actors face what they call a "wall of unpredictability" (At, PM) that destabilize design as well as project management processes.

The next section will highlight and categorize the drivers of exploration that have emerged from data analysis.

\section{Exploration drivers throughout the project}

In this section, the objective is to draw up the inventory of the drivers that underlie exploration through the long course of the NewSFR project, i.e. the motives that orientate the project towards exploration, as they have been revealed by data analysis. The results suggest a broad influence of the following factors: societal, political, regulatory, Human Resources management, identity-related (see Table 3). They intervene jointly in the trajectory of the project and its inflections.

The first driver refers to the sensitivity of the project partners to emerging societal values such as nuclear safety or the reliability of installations. Regarding the future of the nuclear power, in the eyes of the engaged parts, the issue of the social acceptability of any innovation is crucial. 
The second driver, labeled as "political", refers to the major influence of the political sphere (e.g. Ministries, Parliament) on decision-making processes related to the nuclear policy, for example the support and funding provided (or not) for the construction of a demonstrator. If the political authorities have any legitimacy to decide about the future of NewSFR, and the technological option that will be selected, the fact remains that BSC, AtomCo and EnergyCo are the main operators in charge of the NewSFR project and that they are solicited. The political stance is a full part of the power struggles between the mandated partners. The political variable is not without incidence on the industrial constraints on the one hand, and on the validity of the argumentation on the other hand. BSC tends to push explorative technical solutions because they see the disruptive nature of technology as an argument to convince politicians to support this project and its future implementation. Table 3 shows the distinct temporalities between the "experimental reactor" vision and the "industrial demonstrator" vision that maintain ambiguity in the coordination between BSC and AtomCo in particular. Remembering plays a key role in what is regarded as audible, acceptable, or not. The repeated references to the old political choices (notably SFR $\beta$ shutdown) point out the needs for prudence toward politics.

The third driver is regulatory and refers to the fact that safety requirements are real concerns for NewSFR design, especially in view of a future industrialization. This project is permanently under scrutiny of the safety authorities. Yet, the evaluation of the safety of NewSFR is difficult due to the permanent evolution of the regulatory framework combined with the evolution of the reactor itself in relation to emerging exploration. The safety doctrine is, at the same time, powerful and structuring for the inflections of the project (exploitation versus exploration) and the decision criteria. Lastly, between the Fukushima accident and the project NewSFR, a few years have passed. It is obvious that 
in an era post-Fukushima, safety standards have raised in order to take into account both lessons from the accident and the pressure of the authorities. The new safety regulations significantly affect design hypothesis at various levels: components, flows, peripherals. That means a more expansive project and increased complexity in every step of the innovation process and in every knowledge area: the architecture, design, industrialization, reliability, structural building, and operations.

The fourth driver, linked to human resources issues, refers to the evolution of the skills and competences mastered by the design teams and the difficult knowledge transfer from generation to generation within an industry marked by a long temporality. This question is crucial for the project management and learning dynamics within it. However, there is a shift in the approach to the problem, depending on the specialty of the actor involved: R\&D, industrial design, and operation. From the lens of the BSC, mainly specialized in research and development, the turn-over is determining. Its members and skills have been largely renewed and there is a clear gap in knowledge and remembering, which is felt by the actors. It seems that a cumulated loss of knowledge weighs on the evolution of the project NewSFR. It arises from our data that the operation preoccupation has progressively disappeared from the project agenda, for the benefit of two omnipotent concerns: R \& D and industrialization. The departure of generations of experienced engineers and managers, who have not been replaced, clearly induces emerging exploration for two main reasons: (i) the announced disappearance of a heritage of knowhow and competences dedicated to the requirements and realities of SFR operations ${ }^{9}$; (ii) the absence of the major actor in charge of operation in the institutional configuration of NewSFR. Data show that concerns for operation are less and less addressed in the

\footnotetext{
${ }^{9}$ This phenomenon is known in literature as "organizational forgetting", and has already been studied in the French nuclear industry (Garcias, 2014)
} 
innovation process. AtomCo managers regret the gradual disappearance of the operation dimension, which used to ensure industrial realism and feasibility. EnergyCo was seen as a partner powerful and competent enough to counteract innovative (and sometimes farout) ideas from BSC.

"As I explained before, EnergyCo was a lot more present before and it had really a great moderating effect on the new ideas of BSC. Gradually, EnergyCo withdraws itself because its staff was rather old, and retired without being replaced. There is no renewal of SFR competences within EnergyCo, it's sure ... officially to EnergyCo, the project NewSFR is still important strategically but in the facts, they are almost not involved anymore, thus we really lack the operator eye." (Ar, CEM)

The operator was in a position to lead the strategy of the project thanks to the substantial knowledge base and lessons drawn from the operation of previous or existing nuclear reactors. In other words, it is reasonable to suggest that the gradual withdrawal of the operator, and hence the diminution of knowledge related to operation, partly explains emerging exploration and the back and forth movements between different technical solutions, rather classical or innovative.

"EnergyCo brought two things in the preliminary draft: a strategic vision based on a strong and legitimate knowledge base, and, in a more operational way, there were people who had lived either the operation of SFR $\beta$ or other reactors who were able to bring the operator eye. It is fundamental when designing a new reactor. And gradually these people have gone away. They are not replaced with persons of equal experience and capabilities thus the operator eye [...] is progressively lost. And to me it is a handicap in the current stage of the project." (At, CEM)

Finally, the occupational driver refers to the ambiguous status that characterizes this complex project. This driver is linked to identity issues, and mainly the fact that the role of project director is entrusted to an organization whose core business is R\&D. To 
paraphrase a famous sentence of a NASA director involved in the Challenger program, it seems difficult for BSC members to take off their research hat and to put on their project management hat. The definitional controversy around NewSFR status (experimental reactor versus industrial demonstrator) and the ambiguities related to the definition of the goals of the NewSFR project affect the scope and scale of exploration and make interorganizational coordination within the project even more complex. Table 3 below shows the continuing disputes and misunderstandings about the nature and the extent of this project. These ambiguities and related uncertainties induce exploration learning. The doubts expressed by our informants about the finality of this project have organizational consequences: the mode of governance of the project seems to value the experimental version at the expense of the "industrial demonstrator" version.

Secondly, the dual organizational position of BSC (architect and project director) confers to its members a leading role in project coordination, which enables them to promote their own goals oriented mostly towards research in coherence with their main occupational role. For this reason, we observe a propensity to take less into account the criteria of industrialization and operation when designing the future Generation IV reactor.

Table 3: Description of NewSFR from interviews highlighting the different types of drivers

\begin{tabular}{|c|c|c|}
\hline Data source & $\begin{array}{l}\text { Types of } \\
\text { driver }\end{array}$ & Verbatims \\
\hline $\begin{array}{l}\text { Interview } \\
\text { At PM, } \\
2016\end{array}$ & Societal & $\begin{array}{l}\text { "We did not say 'no' to doing these two years [of R\&D on ECS-gas] } \\
\text { because we still remain sensitive to the idea that maintaining the three } \\
\text { strengths of NewSFR is important vis-à-vis stakeholders, the civil society... } \\
\text { on the societal side, it is not stupid to work on a system of energy } \\
\text { conversion, a nuclear reactor that finally secures a little everyone." }\end{array}$ \\
\hline $\begin{array}{l}\text { Interview } \\
\text { At, CEM, } \\
2015\end{array}$ & Political & $\begin{array}{l}\text { "We are always in a political game where the BSC is persuaded that if it } \\
\text { presents the water-steam one, it won't be accepted [by politicians], } \\
\text { therefore it always presents gas as the miracle solution while knowing that } \\
\text { the gas is more expensive, is much less developed, that its horizon of } \\
\text { industrial implementation is not the same... We are always in this } \\
\text { ambiguity there." }\end{array}$ \\
\hline $\begin{array}{l}\text { Interview } \\
\text { TSO, SE1, }\end{array}$ & Regulatory & $\begin{array}{l}\text { "We must decline all the safety requirements to ensure that the reactor } \\
\text { ensures the good level of safety, knowing that this level of safety evolves in }\end{array}$ \\
\hline
\end{tabular}



processes or because of the regulation evolution, for example postFukushima. But anyway the regulation, the safety framework is always evolving."

\begin{tabular}{|c|c|c|}
\hline $\begin{array}{l}\text { Interview } \\
\text { At, CEM, } \\
2016\end{array}$ & $\begin{array}{l}\text { Human } \\
\text { resources }\end{array}$ & $\begin{array}{l}\text { "At the organizational level... gradually the rows of EnergyCo staff are } \\
\text { sparse. At the eve of the NewSFR project launch, there was a quite } \\
\text { important presence of EnergyCo in the project. They either were detached } \\
\text { to NewSFR project team with the BSC, or they came in support during the } \\
\text { meetings or for specific design questions. [...] And progressively, these } \\
\text { people who were experienced workers of the SFR sector have left, have } \\
\text { retired, without being replaced. And from my point of view, it is a large } \\
\text { handicap for the future of the project insofar as EnergyCo always brought } \\
\text { a real added value in terms of operation and also a real added value in } \\
\text { terms of experience of SFR operator. They had both hats: operator in the } \\
\text { broad sense and SFR learning from experience. And progressively we } \\
\text { feel that this operation dimension tends to become secondary and AtomCo } \\
\text { cannot replace it and neither BSC... they are in charge of small } \\
\text { experimental installations, they do not have the very, very, rich operation } \\
\text { experience. For me it is currently a handicap for the progress of the } \\
\text { NewSFR project ... the 'operator hat' is not taken sufficiently into } \\
\text { account." }\end{array}$ \\
\hline $\begin{array}{l}\text { Interview } \\
\text { At FA, } 2016\end{array}$ & $\begin{array}{l}\text { ccupational } \\
\text { Identity }\end{array}$ & $\begin{array}{l}\text { "The problem is that the architect and lead constructor is rather a } \\
\text { research- and technology-oriented organization. As a result, the gas- } \\
\text { based solution for the turbine is much more 'enjoyable' than the turnkey } \\
\text { water and vapor solution supplied by Alstom. It is much more challenging } \\
\text { to explore new compact exchangers since technologies related to these } \\
\text { components are fascinating! [...] It is great for scientists, ok, but it } \\
\text { becomes a technological object much more than an industrial object." }\end{array}$ \\
\hline
\end{tabular}

To temporarily conclude, data analysis reveals that emerging exploration arises from (i) an ambiguous and moving project status and (ii) inter-organizational project management supervised by BSC, whose core business is research and development, and not industrialization or operation. The major institution BSC tallies the terms of exploration; the partners of the program thus have to define local regulations likely to attenuate the tensions that this moving statutory assignment generates. The dominant definition carried by BSC induces lots of constraints on the other partners, and finally on design processes and on project management at a macro-level. 


\section{DISCUSSION - LESSONS FOR THE MANAGEMENT OF HYBRID PROJECTS}

The literature on project management postulates a 'uniformity' in the kind of learning processes within a project, whether this uniformity is specific to a 'stage' of NPD (in the “stage-gate process" approach, (Cooper, 1983)), or to a type of projects (exploitative or exploratory) in the contingent approach of project management (Howell et al., 2010; Lenfle, 2008). On the contrary, our work shows that exploration and exploitation can be closely intertwined, at the same time, within the same project. Our results confirm the perspective opened by the identification of "hybrid projects" (Chandrasekaran et al., 2015), as well as the characterization by Davies \& Brady (2016) of "complex projects" as "agglomeration" of different types of learning processes and activities.

This third category of hybrid projects raises questions about the appropriate management mode since one of the contributions of the contingent approach (as of the stage-gate process approach) is to differentiate project management methods depending on the dominant type of learning, explorative or exploitative. Labeling at the "macro" level of the project may therefore lead to masking a variety of learning mechanisms and ultimately lead to adopt inappropriate management methods.

In order to dive into these project management challenges, we propose to adopt a knowledge area level of analysis to be able to "dig into" project subsets. Our methodological approach adopting an internal point of view, thanks to a privileged access to field study, made possible this variation in levels of analysis. By thus opening up the "black box" of projects, we are able to analyze specifically the dynamics of hybridization of exploration and exploitation within the same project. Complementing our macro-level analysis with a micro-level led us to show that not all knowledge areas that will require exploration are identified and known at the beginning of a project (what we call 
“deliberate exploration"). Some are emerging (what we call "emerging exploration") and appear during the course of the project, thus constantly redefining the balance between exploration and exploitation within a project. Emphasizing these "emerging exploration" dynamics thanks to a temporal focus of project management (Engwall, 2003) enlarges our understanding of the entanglement between exploratory and exploitative processes and how it occurs, and more broadly complements the literature on organizational ambidexterity (Andriopoulos \& Lewis, 2008). This is the first contribution of this research.

The ambiguity we underline to label a project as either explorative or exploitative is rooted in the temporal processes of the project revealing some area in which there are more unknowns than anticipated and opening of options worth to explore. In doing so, our work on "hybrid projects" complements those led by Davies \& Brady (2016) who, in the wake of Lenfle \& Loch (2010), have shown that very large "complex projects" agglomerate "innovative" as well as "routine" modules or sub-projects. In this, "complex projects" escape the dichotomy between exploration and exploitation and present a hybrid character. Adding to this prior research, our work shows that exploratory modules can arise during the project (emerging exploration), not because conditions are changing, but because the overall identity of the project remains unclear. Some participants orient the project towards an exploratory direction through breakthrough technical decisions. In turn, these decisions increase the level of uncertainty surrounding the nature of the project, without any central actor being able to set a clear course. This interplay between the overall project identity and the dynamics of the subsets or areas of knowledge constitutes the second contribution of this article. 
This result calls into question the assumption of the progressive uncertainty reduction in projects, with a gradual decline of the exploratory dimension over time. On the contrary, we show that projects can be characterized by a turbulent trajectory of increasing exploration, which differs from the "funnel" often presented in the literature. This trajectory can be usefully compared to "strange projects" that Lenfle (2016) describes in the space industry. Indeed, managers and designers of AtomCo clearly express this sense of strangeness when they explain that the goals, which were not clear at the beginning, appear less and less clear, that deadlines and schedules are evolving all the time and that they have to work on new concepts, which modify the status of the object and make its industrialization more and more unlikely. Yet, what differs from the case described by Lenfle is the fact that this "strangeness" is not totally perceived from the beginning but rather increases as the project unfolds. Lenfle's work help in understanding the difficulties encountered when designing nuclear objects (especially by the industrial AtomCo). These objects present three features that advocate for a phased approach, classical of the rational project management model: technical complexity of the object, very high cost and irreversibility. In the specific case of nuclear reactors, we must add major safety issues to these three features and the obligation for designers to demonstrate to safety authorities the robustness of technical choices. Historically, this demonstration process is highly structured through different phases, and tends to reinforce the phased approach aiming at controlling, besides safety, more classical project management requirements such as cost and delays and quality. Yet, this rational model is not appropriate to manage exploratory projects, and this mismatch leads actors to label projects as "strange". We come back to that issue when discussing managerial implications. 
We show in our analysis at a micro-level that the identification at the beginning of the project of some areas requiring exploration processes seem to increase the possibility for team members to open up exploration processes on other areas. We identify what are the main "drivers" likely to induce emerging exploration over a project. We emphasize the societal and political issues and the regulatory / safety dimension of nuclear activity as first drivers of emerging exploration. Though this is probably particularly amplified in nuclear project, such drivers may be found in other sectors strongly impacted by environmental or safety regulation such as automotive industry, food industry and / or mainly funded by public administrations such as weapons industry for example. The last two drivers, i.e. 'human resources' and 'occupational identity' refer to the differences between the actors involved in the governance of the project and their respective agenda. Questioning project governance implies qualifying the nature of relationships between the actors, by stressing power and identity-related issues. As we have shown before, they greatly influence the roles and work and cooperation practices of the different actors involved in the project, and thus the project status and trajectory. Though we stress the differences between BSC, EnergyCo and AtomCo, which may appear very specific to these organizations, differences of a comparable magnitude may be found in joint projects between various partners.

The identification of these various drivers suggest to consider the project at a meso-level, influenced by a macro-level encompassing the regulation and the partners strategic agendas and nurtured by a micro-level at which technological hurdles and opportunities are identified. Managing such hybrid project should probably monitor these macro and micro level evolutions and reassess the goals and balance between exploration and exploitation along the course of the project. 


\section{Managerial contributions}

Such projects raise managerial issues at two main levels: the management of knowledge domains with very different levels of uncertainty on the one hand; the modalities of the overall project steering on the other hand. Our research confirms previous work, but it also opens an important field of investigation and calls for additional research.

First, it appears that the management of hybrid projects calls for a differentiated management. A major challenge is to transpose the contingent approach, now well identified in the field of project management, to knowledge areas within a single project. In doing so, our work is in line with the one of Davies and Brady (2016) who argue for the need to build "dynamic capabilities" in order to manage complex projects, which translates here into an ability of project members to navigate between different learning logics depending on the exploratory or exploitative nature of knowledge areas within the project. Once these exploration and exploitation areas are identified, they demand to follow different management logics. The overall project can thus be managed as a set of subprojects obeying different logics.

However, the main difficulty in managing hybrid projects lies in the ability of steering committees to achieve strategic alignment of project stakeholders, who belong to different organizations. Recent research (Loch, et al. 2017) has highlighted the important role of steering committees (SC) for keeping so-called "difficult" projects on track, despite limited expertise and time. Strategic alignment, goal agreement, intelligence gathering or managing surprises are among the major challenges for the SC. This entails notably articulating conflict of interests, clear decision making processes, building "win-win" logic among different stakeholders, investing in focused understanding or establishing 
problem-solving procedures at the outset. Clearly, most of these recommendations are only very partially implemented in the NewSFR project. In particular, AtomCo project members express difficulties in understanding the reasons and consequences of changes (and associated risks), in challenging assumptions or in translating technical terms into business language to make clear and better informed decisions. But these "good practices" seem all the more difficult to bring together in the NewSFR project. In this case, it is not so much about project teams and steering committees members who do not "fully understand" the project, but rather about actors who do not even share a common definition of the project. We show that the project is, from the outset, designed as hybrid, with ill-defined goals, which allows it to evolve towards always more exploration. This hybridization is fostered by, as well as reflected in, the choice of a consortium structure to steer the project that involves actors oriented towards a research logic (BSC) and others towards an industrial and more exploitative logic (AtomCo). Here, the conflict of interest is neither about resources allocation nor value sharing, but about the very identity of the project and the dominant learning logic. In these conditions, strategic alignment can only be achieved through the search for a compromise, or by the "victory" of one of the main actors over the others, the winner then submitting the entire project to his own vision. The case study does not provide, as it stands, keys for steering processes that would integrate exploration and exploitation issues instead of opposing them. However, we can deduce from this case that steering processes should aim at building a shared understanding on the logic of the project, how it may evolve and its key drivers, based on truthful and open discussions. Contrary to the case studied by Loch et al. (2017), the difficulty here is that the project involves several organizations with different organizational goals and interests. In this case, we can conclude that assigning the responsibility of steering a 
project of "industrial demonstrator" to a research institution caused from the beginning a situation that generates both ambiguities and hybridizing processes.

\section{Limitations and avenues for further research}

As we have said, our case highlights a lack of specific steering, which will require further research in order to identify what could be the contours of a hybrid governance adapted to projects of this type, asking in particular if strategic alignment can be achieved within hybrid projects, either through a logic of compromise or by resolving the conflict of vision between actors.

In addition, from a methodological point of view, our data set has limitations, mainly due to accessibility issues. The main limit is that we did not interview the directors of the NewSFR project, who belong to the BSC. Unlike AtomCo and TSO, this organization is not a direct partner of the research program, thus researchers do not have a direct access to these key actors. Consequently, we do not have the BSC's vision on NewSFR project dynamic. These limits affect the interpretations of results, while suggesting directions for further research.

Finally, an important question concerns the contingency or not of the main results (hybridization of exploration and exploitation, emerging nature of exploration, turbulent process rather than funnel-shaped) to certain types of very large multi-organizational projects, with high complexity levels. Note that while this case study is in the nuclear industry, and if it contains many projects with these characteristics, it is not the only one. Aerospace, defense, major infrastructure works, for example, may also have these characteristics and present specific difficulties. Intersectoral comparative studies might 
help to establish the extent to which our results are generalizable outside the nuclear industry.

\section{CONCLUSION}

We started this article by pointing out that the literature on project management is growingly structured around the dichotomy between exploitation projects, managed through classic rationalist approaches, and exploration projects, requiring other rationalities and methods (Lenfle, 2016). Through an in-depth qualitative study of a newgeneration nuclear reactor development case, we introduced the idea that projects can have characteristics that make them difficult to capture using these usual categories. Our main contribution is thus to introduce the notion of "hybrid project", and to identify the main dynamics and characteristics of such projects. Our results show that these projects are subject to unclear and contradictory understandings by the actors and organizations involved. This vagueness and these contradictions open the way to plural and ambivalent technological trajectories within the same project, which we analyze through the categories of 'deliberate exploration' and 'emerging exploration'. The concept of emerging exploration breaks with the common view of a necessary decrease in the degree of unknown over time, including in exploratory projects, and sheds light on the temporal dynamics of hybrid projects. Replacing the project in its socio-temporal trajectory enables to identify the main drivers of emerging exploration, and finally of the hybrid nature of a project.

Lastly, our contributions are part of a larger movement within the project management literature, focusing increasingly on extremely singular projects with complex trajectories and for which steering methods are difficult to define. Previous work has focused on 
“mega-projects” (Flyvbjerg et al., 2003), “complex projects" (Davies and Brady, 2016) or "strange projects" (Lenfle, 2016), offering tools to conceptualize and govern highly specific (or even "chimeric") projects. With the category of "hybrid project", we are clearly in line with this stream of research, with a particular emphasis on the conflicting views surrounding the same project, and ultimately on an indeterminacy that can be perpetuated over time. In our view, these phenomena can be explained, as a last resort, by the fact that these projects take place in long-term socio-organizational trajectories that are themselves complex and ambivalent. In doing so, our contributions can be understood as a response to Engwall's (2003) desire to no longer consider projects as "islands", but to take more account of the institutional surroundings and the long-term trajectory (history and future) in which they develop.

\section{ACKNOWLEDGMENTS}

We would like to thank the ANR and the Investissement d'Avenir program that funded the AGORAS research project in which this study has been carried out. For their helpful comments and advice, we want to express our gratitude to the members of the operational committee and to the reviewers and editors. Finally, a special thank you goes to our informants for their friendship and patience over the last 4 years.

\section{REFERENCES}

Andriopoulos, C., \& Lewis, M. W. (2008). Exploitation-Exploration Tensions and Organizational Ambidexterity: Managing Paradoxes of Innovation. Organization Science, 20(4), 696-717. 
Brady, T., \& Davies, A. (2004). Building project capabilities: from exploratory to exploitative learning. Organization studies, 25(9), 1601-1621.

Chandrasekaran, A., Linderman, K., \& Schroeder, R. (2015). The role of project and organizational context in managing high- tech R\&D projects. Production and Operations Management, 24(4), 560-586.

Clark K. \& Fujimoto T. (1991). Product developement performance. Strategy, organization and management in the world auto industry, Harvard Business School Press.

Clark, K. B., \& Wheelwright, S. C. (1992). Revolutionizing product development: quantum leaps in speed, efficiency, and quality. New York, NY: Free Press.

Cooper, R. G. (1983). A process model for industrial new product development. IEEE Transactions on Engineering Management(1), 2-11.

Davies, A., \& Brady, T. (2016). Explicating the dynamics of project capabilities. International Journal of Project Management, 34(2), 314-327.

Duncan, R. (1976). The Ambidextrous Organization: Designing Dual Structures for Innovation (North Holl ed.). New York: North-Holland.

Eisenhardt, K. M., \& Graebner, M. E. (2007). Theory Building from Cases: Opportunities and Challenges. Academy of Management Journal, 50(1), 25-32.

Engwall, M. (2003). No project is an island: linking projects to history and context. Research policy, 32(5), 789-808.

Eriksson, P. (2013). Exploration and exploitation in project-based organizations: Development and diffusion of knowledge at different organizational levels in construction companies. International Journal of Project Management, 31, 333-341. 
Flyvbjerg, B., Bruzelius, N., \& Rothengatter, W. (2003). Megaprojects and Risk: An Anatomy of Ambition: Cambridge University Press.

Garcias, F. (2014). Apprentissage, désapprentissage et réapprentissage organisationnels: Le cas d'une activité d'ingénierie de grands projets complexes (Doctoral dissertation, Paris, Mines ParisTech).

Garcias, F., Dalmasso, C., \& Sardas, J.-C. (2015). Paradoxical Tensions in Learning Processes: Exploration, Exploitation and Exploitative Learning.M@n@gement, 18(2).

Gephart, R. P. (2004). Qualitative research and the Academy of Management Journal. Academy of Management Journal, 47(4), 454-462.

Greve, H. R. (2007). Exploration and exploitation in product innovation. Industrial and Corporate Change, 16(5), 945-975.

Gupta, A. K., Smith, K. G., \& Shalley, C. E. (2006). The Interplay Between Exploration and Exploitation. Academy of Management Journal, 49(4), 693-706.

Howell, D., Windahl, C., \& Seidel, R. (2010). A project contingency framework based on uncertainty and its consequences. International Journal of Project Management, $28(3), 256-264$.

Katila, R., \& Ahuja, G. (2002). Something old, something new: A longitudinal study of search behavior and new product introduction. Academy of Management Journal, $45(6), 1183-1194$.

Lenfle, S. (2008). Exploration and project management. International Journal of Project Management, 26(5), 469-478.

Lenfle, S. (2016). Floating in Space? On the Strangeness of Exploratory Projects. Project Management Journal, 47(2), 47-61. 
Lenfle, S., Loch, C. (2010). Lost roots: how project management came to emphasize control over flexibility and novelty. California Management Review. 53(1), 32-55.

Li, Y., Vanhaverbeke, W., \& Schoenmakers, W. (2008). Exploration and exploitation in innovation: Reframing the interpretation. Creativity and innovation management, $17(2), 107-126$

Loch, C., Mähring, M., \& Sommer, S. (2017). Supervising projects you don’t (fully) understand: Lessons for effective project governance by steering committees. California Management Review, 59(2), 45-67.

Loch, C., DeMeyer A. \& Pich M., (2006). Managing the Unknown: A New Approach to Managing High Uncertainty and Risk in Projects: John Wiley \& Sons, Inc. New York, NY, USA.

Lundin, R. A., \& Midler, C. (1998). Projects as arenas for renewal and learning processes: Springer Science \& Business Media.

March, J. G. (1991). Exploration and Exploitation in Organizational Learning. Organization Science, 2(1), 71-87.

Midler, C. (1995). "Projectification" of the firm: the Renault case. Scandinavian Journal of Management, 11(4), 363-375.

Nerkar, A. (2003). Old is gold? The value of temporal exploration in the creation of new knowledge. Management science, 49(2), 211-229.

Reid, S. E., \& De Brentani, U. (2004). The fuzzy front end of new product development for discontinuous innovations: A theoretical model. Journal of product innovation management, 21(3), 170-184.

Rowley, J. (2002). Using case studies in research. Management research news, 25(1), 1627. 
Sethi R. and Iqbal Z. (2008). Stage-Gate Controls, Learning Failure, and Adverse Effect on Novel New Products Journal of Marketing, 72:1, 118-134

Shenhar, A. J. (2001). One size does not fit all projects: Exploring classical contingency domains. Management science, 47(3), 394-414.

Yin, R. K. (1993). Applications of case study research: London: Sage. 